\title{
Out-of-hospital cardiac arrest in countries of the Gulf Cooperation Council: a scoping review
}

Alan Batt, ${ }_{1}$ Chelsea Lanos, ${ }^{2}$ Shannon Delport, ${ }^{3}$ Dalal Al-Hasan, ${ }^{4}$ Shane Knox,${ }^{5}$ Assim Alhmoudi, ${ }^{6}$ Megan Anderson, ${ }^{1}$ Saleh Fares ${ }^{7}$ and Fergal Cummins ${ }^{8}$

${ }^{1}$ Fanshawe College, London, Ontario, Canada. ${ }^{2}$ County of Renfrew Paramedic Service, Pembroke, Ontario, Canada. ${ }^{3}$ CQUniversity, Rockhampton, Queensland, Australia. ${ }^{4}$ Department of Applied Medical Sciences, Health Sciences College, Public Authority of Applied Education and Training, Kuwait. ${ }^{5}$ National Ambulance Service College, Ballinasloe, Ireland. ${ }^{6} \mathrm{Abu}$ Dhabi Police, Sheikh Zayed Road, Al Muroor, Abu Dhabi, United Arab Emirates. ${ }^{7 Z a y e d}$ Military Hospital, Abu Dhabi, United Arab Emirates. ${ }^{8}$ University of Limerick, Castletroy, Limerick, Ireland. (Correspondence to: Alan Batt: abatt@ fanshawec.ca).

\begin{abstract}
Background: Published data are lacking on response to and outcomes of out-of-hospital cardiac arrest in the Middle East. What data there are have not been comprehensively analysed.

Aims: This study aimed to assess the characteristics of people with out-of-hospital cardiac arrest in Gulf Cooperation Council (GCC) countries (Bahrain, Kuwait, Oman, Qatar, Saudi Arabia and United Arab Emirates) and the response to and outcomes of such incidents.

Methods: This was a scoping review of published and grey literature on out-of-hospital cardiac arrest in GCC countries from 1990 to June 2019. Studies in English and Arabic were eligible for inclusion. MEDLINE, CINAHL, Web of Science and EMBASE were searched as well as relevant non-indexed journals. Google searches were also done. References of included studies were scanned for relevant articles. Experts on the subject in the region were consulted.
\end{abstract}

Results: Of 647 citations retrieved, 24 studies were included for data extraction and analysis. No literature was identified for Bahrain. People with out-of-hospital cardiac arrest in the region were younger, predominantly male and had more comorbidity than reported in other regions of the world. Use of emergency medical services was low across the GCC countries, as was bystander cardiopulmonary resuscitation, return of spontaneous circulation and survival to discharge.

Conclusions: A coordinated effort to address out-of-hospital cardiac arrest, including the generation of research, is lacking within and among GCC countries. Establishment of lead agencies responsible for developing and coordinating strategies to address out-of-hospital cardiac arrest, such as community response, public education and reporting databases, is recommended.

Key words: out-of-hospital cardiac arrest, emergency medical services, cardiopulmonary resuscitation, Gulf Cooperation Council, Middle East

Citation: Batt A; Lanos C; Delport S; Al-Hasan D; Knox S; Alhmoudi A; et al. Out-of-hospital cardiac arrest in countries of the Gulf Cooperation Council: a scoping review. East Mediterr Health J. 2021;27(7):707-717. https://doi.org/10.26719/emhj.20.141

Received: 10/02/20; accepted: 08/09/20

Copyright (C) World Health Organization (WHO) 2021. Open Access. Some rights reserved. This work is available under the CC BY-NC-SA 3.0 IGO license (https://creativecommons.org/licenses/by-nc-sa/3.o/igo).

\section{Introduction}

Out-of-hospital cardiac arrest is a major cause of mortality worldwide, with variable survival reported across countries and systems. In particular, Middle-Eastern and South Asian countries report low survival rates (1). Reported reasons for low survival from out-of-hospital cardiac arrest in these settings include unique demographic, cultural and logistical challenges related to the management of out-of-hospital cardiac arrest. At the same time, most of the evidence used to inform resuscitation guidelines for out-of-hospital cardiac arrest comes, for the most part, from very different systems, and applying this evidence and guidelines in Middle-Eastern settings may also present a challenge.

Characteristics and outcomes of out-of-hospital cardiac arrest in Middle-Eastern countries are still poorly researched, thus compounding these challenges. The resulting lack of knowledge prevents us from understanding the factors related to out-of-hospital cardiac arrest, and thereby prevents us from improving response to and outcomes of out-of-hospital cardiac arrest in these countries. Thus, to meaningfully tackle out-of-hospital cardiac arrest in the Middle East, we first need to understand the issue within this context.

The Gulf Cooperation Council (GCC) was established in 1981 and comprises the governments of Bahrain, Kuwait, Oman, Qatar, Saudi Arabia and the United Arab Emirates. The countries in the GCC are predominantly Islamic and they share a common cultural and historical background (2). Another shared trait is their economic reliance on expatriate workforces (3), estimated at $48 \%$ of the total regional population of 53 million $(4,5)$. Within this regional population, life expectancy has risen substantially from $42-61$ years in the 1960 s to 74-80 years in 2018 (5). However, increased population numbers, the health care needs of groups with different demographics and increased life expectancy have led to a rise in health care demand. This rise is predominantly due to high rates of noncommunicable diseases such as 
diabetes, cardiovascular disease and obesity, attributable to unhealthy lifestyles and a general lack of coordinated public health programmes $(4,6)$. In order to reduce the risk of mortality associated with such morbidity, most GCC member countries have initiated public health strategies, which include the recording and reporting of noncommunicable diseases.

The first report on out-of-hospital emergency care in a GCC country was for Abu Dhabi in 2004 (7), when emergency medicine within GCC countries was rudimentary. This study observed no real medical oversight of out-of-hospital care provision, no treatment policies, a lack of training and education, and no quality assurance policies. However, emergency medicine and prehospital care have developed across the GCC countries in the past 15 years.

Reporting of out-of-hospital cardiac arrest rates, response and outcomes are benchmarks of emergency medical response readiness. Therefore, we conducted a review of studies on out-of-hospital cardiac arrest in the GCC to understand their characteristics and properties, and to identify any gaps in the literature and areas for further research.

\section{Methods}

\section{Study design}

We conducted a scoping review, which enabled us to identify, map and present an overview of a heterogeneous body of literature $(8,9)$. We considered a scoping review to be appropriate given the predicted lack of published data (and potential reliance on sources from the grey literature), the anticipated heterogeneity among studies and the expected variability in reporting.

\section{Review process}

We performed a systematic literature search for studies that investigated out-of-hospital cardiac arrest in the GCC region. We used a five-stage framework (8), which included: (i) identifying the research question; (ii) identifying relevant studies; (iii) refining the study selection criteria; (iv) collecting relevant data from each article; and (v) collating, summarizing, reporting and interpreting the results. We also implemented a recommended additional stage: (vi) consultation with experts. We reported our process according to the PRISMA extension for scoping reviews (10).

First, we identified three research questions.

1. What are the characteristics of cases of out-of-hospital cardiac arrest in the GCC region?

2. How do these studies differ from other international studies?

3. What insights can be gained from these findings in order to better inform policy and practice in the GCC region?

Second, to identify relevant studies we undertook a systematic search of the literature. An information scientist (MA) developed the search strategy. We used this to search the electronic databases MEDLINE, CINAHL, Web of Science and EMBASE from 1990 until June 2019. The search strategy was modified accordingly for each database they do not all have the same subject headings. Relevant non-indexed journals were identified and searched, and we performed multiple Google web and Google Scholar searches. We searched the grey literature with guidance from the Grey Matters checklist (11). References of included studies were scanned for relevant articles. See Appendix I for search terms and a list of non-indexed sources.

Third, we established the eligibility criteria. Studies in English and Arabic were eligible for inclusion if they reported out-of-hospital cardiac arrest in the GCC. We excluded studies that were not related to out-of-hospital cardiac arrest (e.g. in-hospital cardiac arrest), case reports, studies that reported only on out-of-hospital cardiac arrest caused by a trauma, studies that were related to cardiopulmonary resuscitation training and those not conducted in GCC countries.

We ( $A B$ and $C L)$ reviewed titles and abstracts of studies retrieved in the search. We resolved disagreements through discussion until we reached consensus. Where disagreement remained or there was insufficient evidence to make a decision, we included the citation for full text review and subsequent decision.

Fourth, to support the full-text review, we developed a standardized data extraction form to organize information, confirm relevance and extract study characteristics (See Appendix II) (12). Two reviewers ( $A B$ and $\mathrm{CL}$ ) abstracted general study characteristics such as authorship, year of publication, country, study design, sample size, outcomes measures and characteristics of out-of-hospital cardiac arrest. We compiled all data for analysis into a single spreadsheet in Microsoft Excel 2013.

Fifth, we summarized and synthesised the data. Because of variations in study designs, terminology used and reporting conventions, we needed to identify common areas for reporting summarized results. We selected a number of demographic, process and outcome measures that reflect key components of an effective response to and management of out-of-hospital cardiac arrest. We abstracted and reported the findings for each measure per study where possible, and we report on them under the headings of characteristics, process and outcomes measures.

In line with the scoping review framework, we did not conduct a critical appraisal (8).

Sixth, in addition to our own experience and expertise with out-of-hospital cardiac arrest in the region, we invited a number of experts on out-of-hospital cardiac arrest in the GCC to contribute additional material and unpublished studies. Two of these individuals subsequently joined the research team (DA and AA). 


\section{Ethical considerations}

This was a scoping review of completed studies and hence no ethics approval was required.

\section{Results}

\section{Search results and study selection}

The search yielded 590 citations. We identified an additional 57 citations through searches of the grey literature and hand searching. After elimination of duplicates, we screened 284 citations at the title and abstract level. This led to the exclusion of 236 citations. After full-text review of 48 citations, we included 24 full-texts for data extraction and analysis (Figure 1). Not all are referenced (some were unpublished at the time, or duplicate reference to technical report) - the full citation for these are included in Appendix III. See Appendix III for details of adult out-of-hospital cardiac arrest studies, and Appendix IV for details of paediatric out-of-hospital cardiac arrest studies.

\section{Characteristics of studies}

The included studies were published between 1999 and 2019 (13-30). The studies were: 16 full-text articles (both published and unpublished manuscripts), three technical reports or theses, three conference abstracts, and two letters to the editor. Ten studies were from the United Arab Emirates), six from Qatar, four from Saudi Arabia, three from Kuwait, one from Oman and one for the region. We did not identify any literature from Bahrain despite consultation with an expert on the subject in the coun- try. Of the 24 studies, 16 (13-27, plus unpublished studies given in Appendix III) described adult cases or all cases of out-of-hospital cardiac arrest. Four studies reported data on paediatric out-of-hospital cardiac arrest (13,28-30) and we report these separately in our results; one study is reported as both an adult and a paediatric study on out-of-hospital cardiac arrest (13). Where results were published in more than one source (for example a technical report and a peer-reviewed manuscript), we only abstracted the most complete version. See Appendix III for details the sources abstracted.

\section{Adult cases}

\section{Characteristics}

Adults who experienced out-of-hospital cardiac arrest in the GCC region were consistently young, predominantly male and often had underlying comorbidities, such as diabetes. Most cases of out-of-hospital cardiac arrest occurred at home (ranging from $54 \%$ to $85 \%$ of all cases of out-of-hospital cardiac arrest). Table 1 and Figure 2 give further characteristics (see Appendix III for details).

We found differences in the characteristics of people who experienced out-of-hospital cardiac arrest among ethnic groups in the region (e.g. Arab, South Asian and North African). For example, compared with GCC nationals with out-of-hospital cardiac arrest, South Asian and North African people with out-of-hospital cardiac arrest were more likely to smoke but had lower levels of comorbidities (17,22). Despite this finding, South Asian and North African people with out-of-hospital cardiac arrest were generally younger and accounted for a large percentage of the total number of cases of out-of-hospital

Figure 1 Flow chart of search results

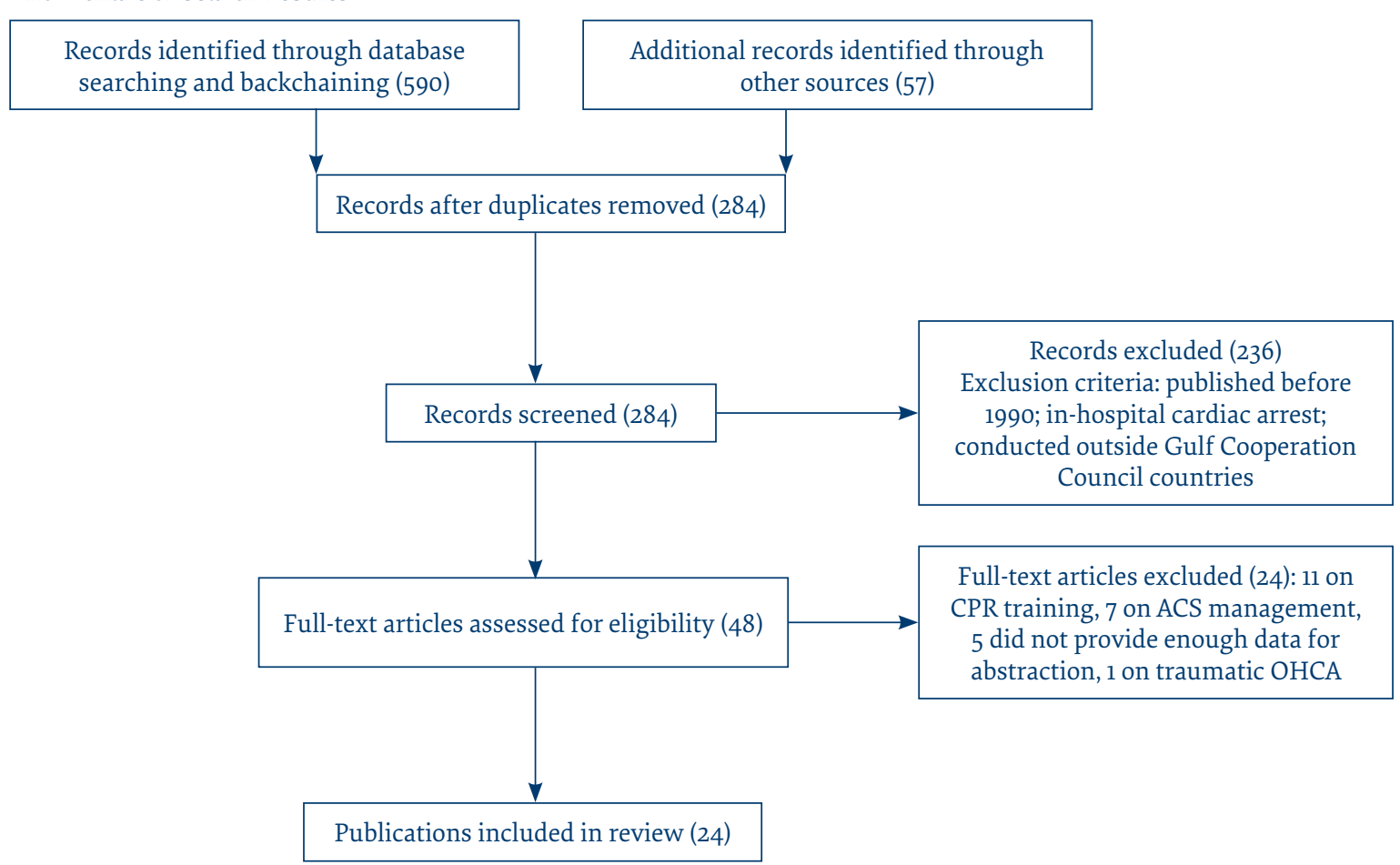




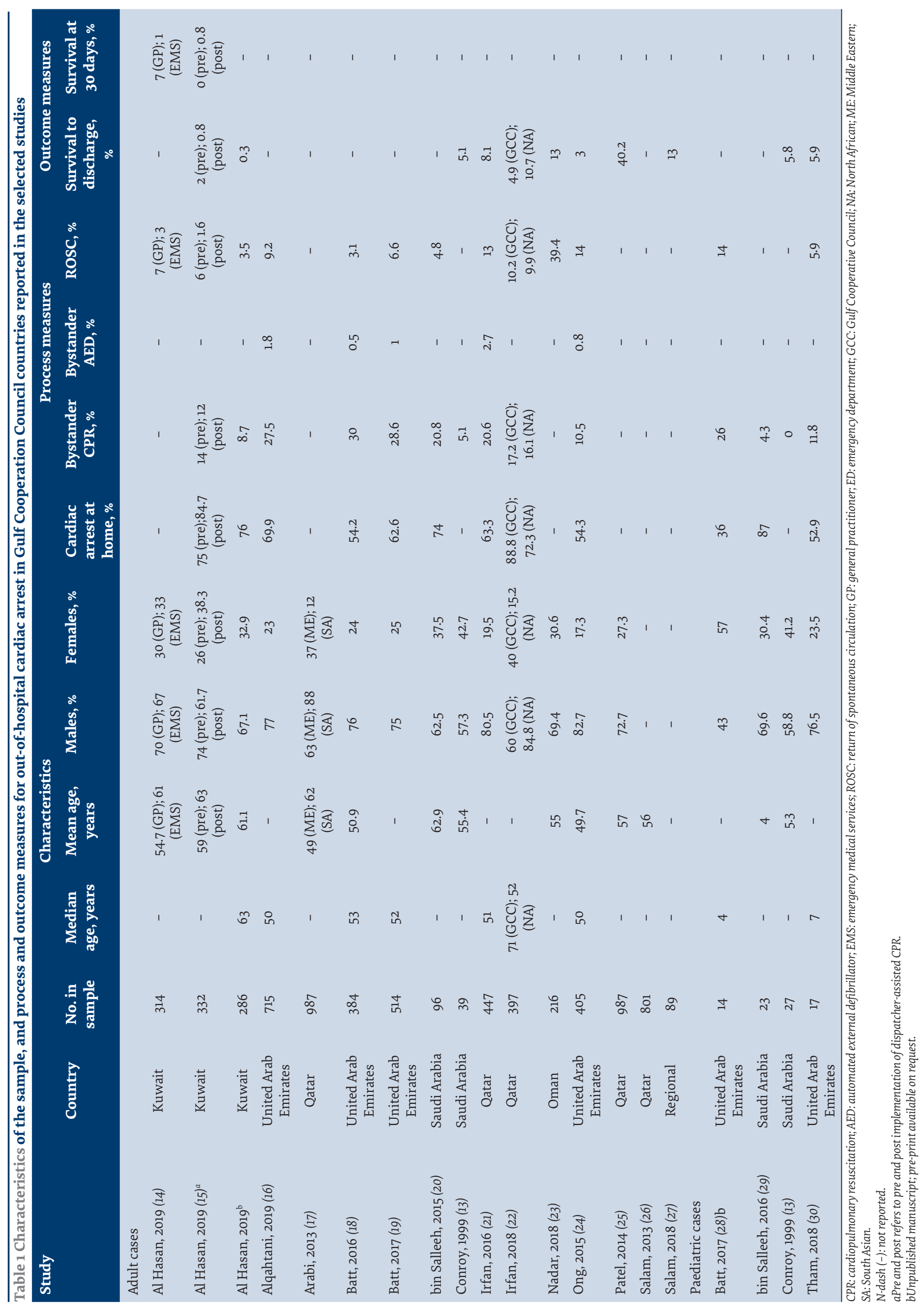




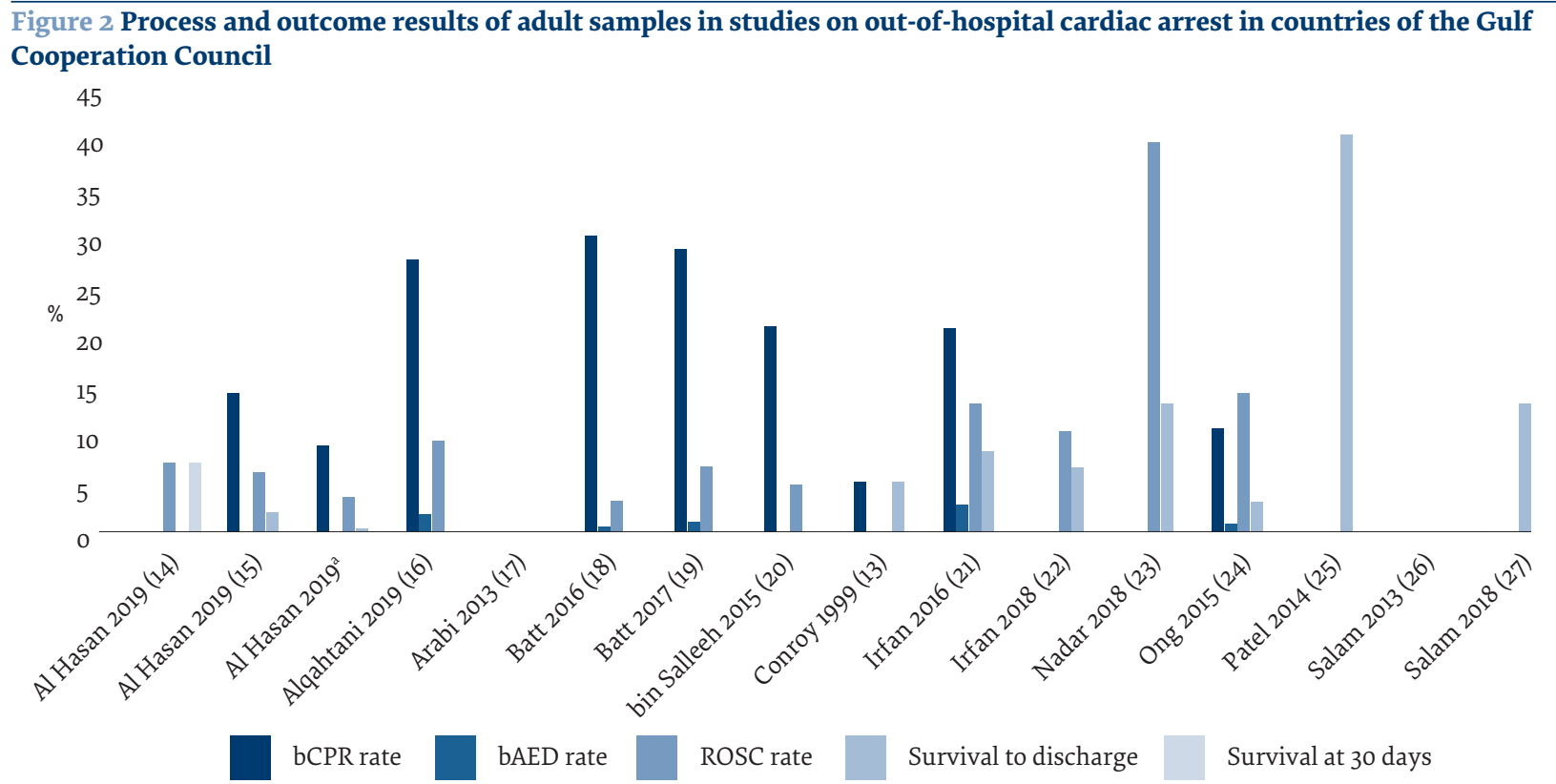

bCPR=bystander cardiopulmonary resuscitation; $b A E D=$ bystander automated external defibrillator; $R O S C=$ return of spontaneous circulation. anpublished manuscript; pre-print available on request.

cardiac arrest in several studies $(16,18,21)$. Data on specific process and outcome measures for national populations were not well reported in the studies.

\section{Process and outcome characteristics}

The use of emergency medical services was low, as was bystander cardiopulmonary resuscitation, rates of return of spontaneous circulation and survival to hospital discharge compared with international figures. The rate of use of emergency medical services was rarely reported, and ranged from $1.4 \%(23)$ to $31 \%(20)$. The rate of bystander cardiopulmonary resuscitation ranged from $5.1 \%$ (13) to $30 \%$ (18). The rate of use of an automated external defibrillator by a bystander was reported at less than $3 \%$ for any study that reported such data. The rate of return of spontaneous circulation ranged from $1.6 \%$ (15) to $39.4 \%$ (23) but most studies reported this rate at less than $10 \%$. The rate of survival to hospital discharge was often not reported and ranged from $2 \%$ (15) to $40.2 \%$ (25); however, most studies reported rates less than $10 \%$ (Figure 2 ).

\section{Paediatric cases}

\section{Characteristics}

Only four studies reported paediatric out-of-hospital cardiac arrest. Children who experienced out-of-hospital cardiac arrest in the GCC were mostly male and the out-of-hospital cardiac arrest in a significant proportion of the cases had a non-medical etiology (23.5-45.0\%), including drowning. Most cases of paediatric out-of-hospital cardiac arrest occurred at home, ranging from $36 \%$ (28) to $87 \%$ (29) of all cases of paediatric out-of-hospital cardiac arrest (Table 1 and Figure 3; see Appendix IV for details).

\section{Process and outcome characteristics}

We observed low rates of: bystander cardiopulmonary resuscitation rates; return of spontaneous circulation rates; survival to hospital discharge rates across the paediatric out-of-hospital cardiac arrest studies in the region (Figure 3). Bystander cardiopulmonary resuscitation ranged from $0 \%$ (13) to $26 \%$ (28). No studies of paediatric out-of-hospital cardiac arrest cases reported the use of automated external defibrillator by bystander. Two studies reported the rate of return of spontaneous circulation, 5.9\% (30) and 14\% (28). Two studies reported a survival to discharge rate of about $6 \%(13,30)$. Pre-existing medical conditions were reported for cases of paediatric out-of-hospital cardiac arrest in several studies and varied from $23.5 \%$ (30) to almost $70 \%$ (29).

\section{Discussion}

The causes of lower survival from out-of-hospital cardiac arrest in the GCC than reported in international studies are anecdotally related to unique demographic, cultural and logistical contexts of the region. Given these challenges, and the lack analysis of the literature, we explored out-of-hospital cardiac arrest in the GCC in a scoping review. The studies we included reported low rates of survival to discharge for out-of-hospital cardiac arrest (1-13\%) when compared with other international studies, e.g. $10-23 \%$ (31). After examining studies from countries in the GCC, we suggest several unique characteristics are associated with out-of-hospital cardiac arrest in the region including characteristics related to process and outcomes. Despite the mortality associated with out-of-hospital cardiac arrest in the region, this condition remains poorly researched, with a lack of a coordinated effort to improve process and outcomes. 
Figure 3 Demographic, process and outcome results of paediatric samples in studies on out-of-hospital cardiac arrest in countries of the Gulf Cooperation Council

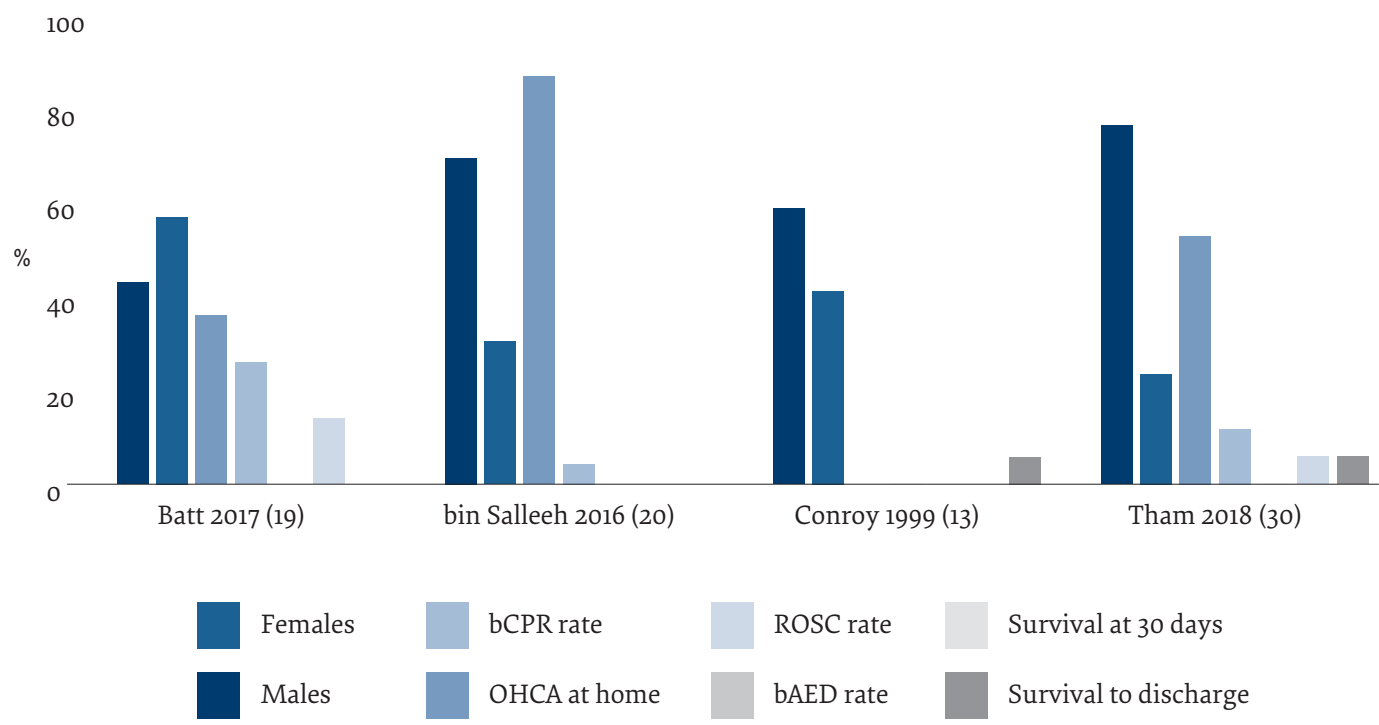

bCPR=bystander cardiopulmonary resuscitation; $b A E D=$ bystander automated external defibrillator; $R O S C=$ return of spontaneous circulation).

\section{Characteristics of out-of-hospital cardiac arrest in GCC countries}

People experiencing out-of-hospital cardiac arrest in GCC countries are predominantly male, and younger and with more co-morbid conditions than those with out-of-hospital cardiac arrest elsewhere $(15,18,20$; see Appendix III for details). We suggest a number of reasons for these findings. One proposed cause for the observed level of cardiac conditions is the so-called obesogenic urbanization that has occurred rapidly in the region as a result of oil wealth (32). A number of studies in our review reported high rates of cardiac risk factors including diabetes mellitus, hypertension, hyperlipidaemia, chronic renal failure and acute coronary syndrome $(17,18,22,23,24,27)$. In addition, the large expatriate populations living in some GCC countries, and their unique lifestyle risk factors (such as high rates of smoking) may have contributed to the observed young age and male dominance of cases of out-of-hospital cardiac arrest in our review $(16,18,21)$. We also observed differences in the demographics of out-of-hospital cardiac arrest in these expatriate populations compared with the national populations (16,18,21; see Appendix III for details). For example, expatriates were normally younger and more likely to smoke compared with nationals $(17,22)$.

\section{Pre-hospital resuscitation}

In the studies we reviewed, most cases of out-of-hospital cardiac arrest occurred at home, which is consistent with international findings (33). Cases of cardiac arrest in public places have generally been reported to have better outcomes in studies conducted outside the GCC (34). This difference is likely because more cardiac arrests are witnessed, early activation of the emergency medical services and early provision of bystander cardiopulmonary resuscitation and automated external defibrillation.
Research shows that early response before the arrival of emergency medical services is crucial in the outcomes of out-of-hospital cardiac arrest, i.e. recognizing out-of-hospital cardiac arrest, calling for help and providing bystander cardiopulmonary resuscitation and automated external defibrillation (34,35). We observed low levels of use of emergency medical services (reported in two studies, range $1.4-35 \%$ ), low bystander cardiopulmonary resuscitation rates (reported in 10 studies, range 3-30\%) and very low bystander use of automated external defibrillators in the studies in our review. Variation in response times and an absence of integrated community response systems mean that death from out-of-hospital cardiac arrest in GCC countries is likely to occur at the scene. These findings highlight a weakness in the public response to out-of-hospital cardiac arrest in the region. Anecdotal reasons for such challenges include a lack of defibrillators in public places, so-called good Samaritan laws that stipulate only certified people should provide medical assistance, lack of governing bodies to oversee all aspects of the medical emergency response, the rural residence of significant portions of the population, and cultural norms (18). Cultural challenges include a lack of knowledge of cardiopulmonary resuscitation, a lack of confidence to intervene, and barriers to cardiopulmonary resuscitation and the use of automated external defibrillators, especially on females experiencing out-of-hospital cardiac arrests (36). We also observed over-reliance on private transport rather than emergency medical services to transport patients with out-of-hospital cardiac arrest, which mirrors results of non-out-of-hospital cardiac arrest studies in the region (37). Attempts to address such challenges are bringing results, as evidenced in the reported increased use of emergency medical services for out-of-hospital cardiac arrest $(16,18,19)$. However, public perceptions on recognizing and intervening in 
out-of-hospital cardiac arrest have yet to be studied in GCC countries.

In other regions, developing integrated community response models has led to substantial improvements in outcomes of out-of-hospital cardiac arrest. Ireland is a good example, and it shares characteristics of rurality in common with GCC countries $(38,39)$, despite their obvious geographical differences. In 2018, 2442 cases of out-of-hospital cardiac arrest were reported in Ireland. Of these cases, $81 \%$ received bystander cardiopulmonary resuscitation (excluding cases witnessed by the emergency medical services), $22 \%$ received bystander automated external defibrillation, $26 \%$ had return of spontaneous circulation and $7.2 \%$ survived to discharge, most of whom had cerebral performance scores of 1 or 2 (40). These results are a significant improvement on the national figures from only 5 years before when 1885 cases out-of-hospital cardiac arrest were recorded, of whom $69 \%$ received bystander cardiopulmonary resuscitation (excluding cases witness by the emergency medical services), $16 \%$ received bystander automated external defibrillation, $23 \%$ had return of spontaneous circulation and $6.3 \%$ survived to discharge (41). In that 5 -year period, Ireland had developed a national network of integrated community response schemes, focused on the provision of early cardiopulmonary resuscitation, including dispatcher-assisted cardiopulmonary resuscitation. As a result, continued improvements in measures of out-of-hospital cardiac arrest are likely in the future. Given the challenges we observed in this review in relation to access to emergency medical services, bystander cardiopulmonary resuscitation, bystander use of automated external defibrillators and cultural and logistical barriers, rates of return of spontaneous circulation and survival to hospital discharge were low across the region. In other words, lower survival as an outcome is reflective of process issues in the resuscitation attempt, particularly in the pre-arrival phase.

\section{Lack of research and coordinated efforts}

The processes and outcomes related to out-of-hospital cardiac arrest are well researched in a number of countries, in part due to established, coordinated cardiac arrest registries. These registries may be national (39) or regional (31), and they allow researchers to examine trends, correlations and concerns related to out-of-hospital cardiac arrest with large prospectively collected datasets. Another example is the Pan-Asian Resuscitation Outcomes Study (PAROS), an international cardiac arrest registry study of which the United Arab Emirates is a reporting member (24). Our review also showed that out-of-hospital cardiac arrest research efforts across the GCC are infrequent, and even within countries, research efforts on out-of-hospital cardiac arrest are not strategically coordinated. For example, none of the existing PAROS studies in the United Arab Emirates reported on out-of-hospital cardiac arrest in Abu Dhabi. Thus, these publications do not present a complete account of out-of-hospital cardiac arrest in the United Arab Emirates. The heterogeneity of populations within PAROS across Asia and the Middle East is a challenge as the aggregated data are not always useful for informing strategies in particular regions such as the GCC (42). In some GCC countries, outcomes of out-of-hospital cardiac arrest are unknown due to a complete lack of reporting. Despite a previous call for a regional initiative for data collection and sharing (43), no concerted effort has been made to create reporting databases for out-of-hospital cardiac arrests in GCC countries. As a result of this lack of coordinated effort, we cannot provide scientific answers to research questions, which creates a barrier to evidence-informed policy- and decision-making in the GCC. Furthermore, the provision of public education, coordination of public information campaigns, improved bystander and community response to out-of-hospital cardiac arrest, strategic planning of emergency medical response and the coordination of research efforts are (where they exist) spread across many local or national agencies within each country. This makes it more difficult to achieve a coordinated effort in the management of out-of-hospital cardiac arrest. Without such strategic oversight, there is potential for duplication of effort, missed opportunities to strengthen the response to out-of-hospital cardiac arrest and a lack of compatibility of findings both within and between countries in the region.

\section{Conclusion}

Given our findings on the characteristics of people experiencing out-of-hospital cardiac arrest in the GGC countries and the response to and management of such incidents, efforts are needed to reduce the burden of cardiac arrest in GGC countries. Such efforts, which largely reflect the recommendations of the Global Resuscitation Alliance (44), include: (i) creation of a lead agency in each country for strategic oversight of preparedness, response, management and research for out-of-hospital cardiac arrest; (ii) development of community response models; (iii) legislation of equivalents to the so-called good Samaritan law (45,46); (iv): implementation of public health initiatives to reduce cardiac risk factors; (v) coordination of public information campaigns on recognition and management of out-of-hospital cardiac arrest, including early access to emergency medical services and early cardiopulmonary resuscitation (47,48); (vi): improvement in access to automated external defibrillators in high-risk locations and creation of national automated external defibrillator registries $(49,50)$; and (vii) establishment and maintenance of registries of out-of-hospital cardiac arrest in each country and the GCC region which align with international conventions (51).

Our findings need to be interpreted in the context of certain limitations. We may not have identified all relevant studies despite our attempts to make a comprehensive search. Our search and review was restricted to articles published in English and Arabic, but this does not inherently bias a review (52). The Google Scholar searches were limited to the first 300 results which is considered adequate for grey literature searches 
(53). Further grey literature sources may exist that we did not identify; however, we attempted to minimize this risk by using the Grey-Matters checklist (11), contacting experts on out-of-hospital cardiac arrest in the region and searching non-indexed sources. A number of studies included data on presumed cardiac etiology as well as traumatic out-of-hospital cardiac arrest. We attempted to identify and report only data on non-traumatic outof-hospital cardiac arrest where possible, but this was not always possible. Finally, there are a few studies on paediatric out-of-hospital cardiac arrest in our review. Despite the limitations associated with such a small number of paediatric studies, we report them here to provide some collective insight into paediatric out-ofhospital cardiac arrest in GCC countries.

Despite these limitations, our review is the first to collate and comprehensively report data on out-ofhospital cardiac arrest in the GCC region and highlights the considerable burden associated with out-of-hospital cardiac arrest in the region. We highlighted unique demographic traits and challenges related to processes and outcomes of out-of-hospital cardiac arrest in the region, as well as the paucity of research on the topic and the lack of a coordinated effort within the region in responding to and managing out-of-hospital cardiac arrest.

\section{Acknowledgement}

Data from this study were presented at the Emirates Society of Emergency Medicine scientific meeting on 13 December 2019 in Abu Dhabi, United Arab Emirates.

Funding: This research was supported by a research grant from the ZOLL Foundation, Massachusetts, USA which had no role in the design or conduct of the study; the collection or analysis of the data; or the drafting or submission of the manuscript.

Competing interests: None declared.

\section{Arrêt cardiaque extrahospitalier dans les pays du Conseil de Coopération du Golfe : étude exploratoire \\ Résumé}

Contexte: Les données publiées sont insuffisantes en ce qui concerne les interventions en cas d'arrêts cardiaques extrahospitaliers et leurs conséquences au Moyen-Orient. Les données disponibles quelles qu'elles soient n'ont pas été analysées de manière exhaustive.

Objectifs : La présente étude avait pour objectif d'évaluer des personnes ayant été victimes d'un arrêt cardiaque extrahospitalier dans les pays membres du Conseil de Coopération du Golfe (Arabie saoudite, Bahreïn, Émirats arabes unis, Koweït, Oman et Qatar) ainsi que les interventions pour ces incidents et leurs conséquences.

Méthodes: Il s'agissait d'une étude exploratoire de la littérature publiée et de la littérature grise sur les arrêts cardiaques extrahospitaliers dans les pays du Conseil de Coopération du Golfe entre 1990 et juin 2019. Les études en anglais et en arabe étaient admissibles à l'inclusion. Des recherches ont été menées dans MEDLINE, CINAHL, Web of Science et EMBASE, ainsi que dans des revues non indexées pertinentes. Des recherches sur Google ont également été effectuées. Les références des études incluses ont été examinées pour trouver des articles pertinents. Des experts de ce domaine ont été consultés dans la Région.

Résultats : Sur 647 citations extraites, 24 études ont été incluses pour l'extraction et l'analyse des données. Aucune littérature n'a été identifiée pour Bahreïn. Les personnes ayant été victimes d'un arrêt cardiaque extrahospitalier dans la Région étaient plus jeunes, principalement de sexe masculin et présentaient davantage de comorbidités que dans d'autres régions du monde. Le taux de recours aux services médicaux d'urgence était faible dans les pays du Conseil de Coopération du Golfe, tout comme la réanimation cardio-respiratoire effectuée par un passant, le retour à la circulation spontanée et la survie jusqu'à la sortie de l'hôpital.

Conclusions: Il existe un manque d'efforts coordonnés pour faire face à l'arrêt cardiaque extrahospitalier, notamment en matière de recherche, au sein des pays du Conseil de Coopération du Golfe et entre eux. Il est recommandé de mettre en place des organismes chefs de file responsables de l'élaboration et de la coordination des stratégies de lutte contre les arrêts cardiaques extrahospitaliers, telles que la riposte communautaire, l'éducation du public et les bases de données de signalement. 


\section{السكتة القلبية خارج المستشفى في بلدان بجلس التعاون الخليجي: استعر اض استكشافي}

ألن بات، تشيلسي لانوس، شانون ديلبورت، دلال الحسن، شين نوكس، عاصم الحمودي، ميجان أندرسون، صالح فارس، فيرجال كامينز

الخلفية: هناكِ نقص فِ فِ البيانات المنشورة حول الاستجابة للسكتة القلبية خارج المستشفى وخرجاتها في الشرق الأوسط. ولم يتم تحليل البيانات الموجودة تحليلاً شاملاً.

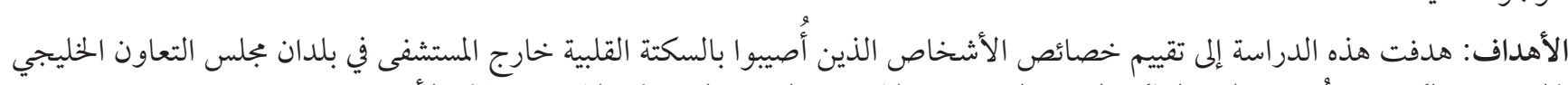

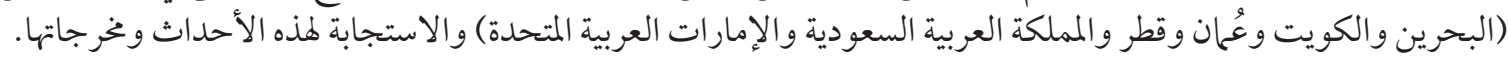

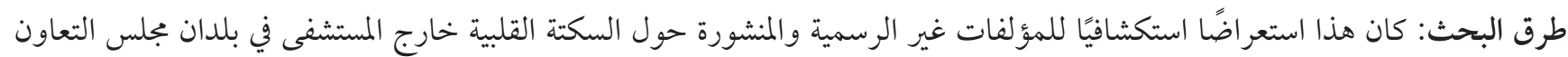

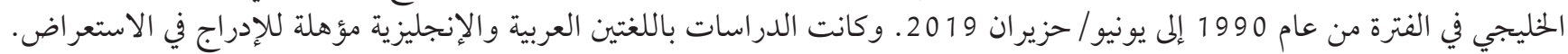

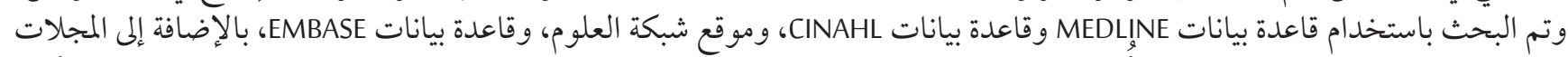

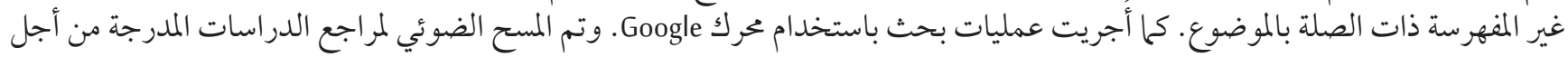

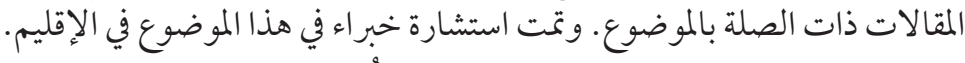

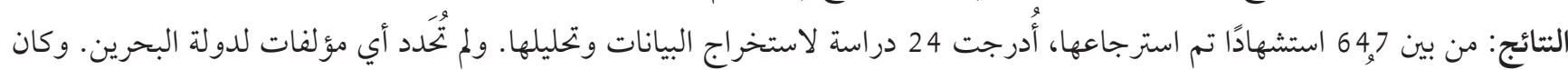

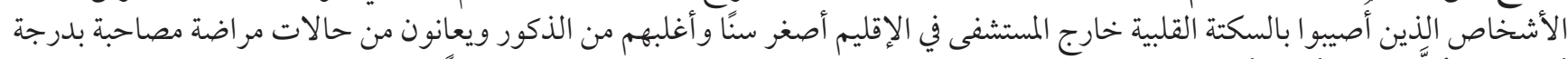

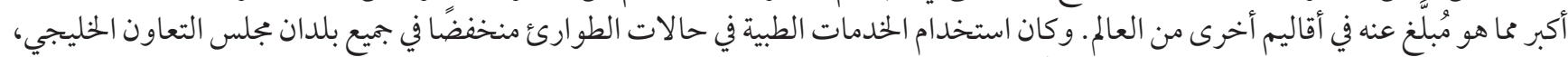

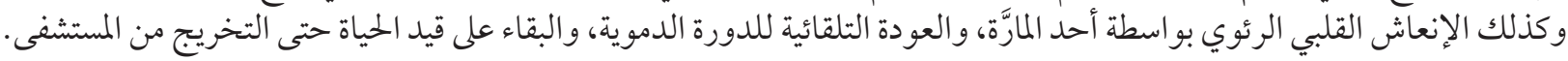

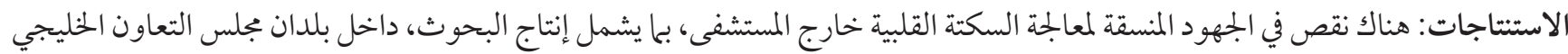

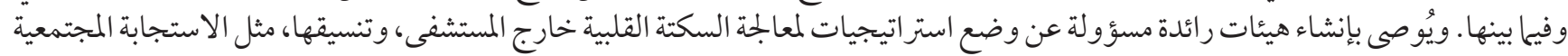
وتثقيف العامة وقو اعد بيانات الإبلاغ.

\section{References}

1. Berdowski J, Berg RA, Tijssen JGP, Koster RW. Global incidences of out-of-hospital cardiac arrest and survival rates: systematic review of 67 prospective studies. Resuscitation. 2010;81(11):1479-87. https://doi.org/10.1016/j.resuscitation.2010.08.006

2. Kirk D, Napier D. The transformation of higher education in the United Arab Emirates: issues, implications and intercultural dimensions. In: Zajda J, Daun H, Saha L, editors. Nation-building, identity and citizenship education: cross-cultural perspectives. Berlin: Springer Science \& Business Media; 2009:131-42.

3. Naithani P, Jha AN. Challenges faced by expatriate workers in Gulf Cooperation Council Countries. Int J Bus Manag. 2010;5(1):98-104.

4. Khoja T, Rawaf S, Qidwai W, Rawaf D, Nanji K, Hamad A. Health care in Gulf Cooperation Council countries: a review of challenges and opportunities. Cureus. 2017;9(8):1-11. https://doi.org/10.7759/cureus.1586

5. World Bank data. Data for Saudi Arabia, United Arab Emirates, Kuwait, Bahrain, Oman, Qatar [internet]. Washington, DC: World Bank; 2019 (https://data.worldbank.org/?locations=SA-AE-KW-BH-OM-QA, accessed 2 December 2019).

6. Razzak H, Harbi A, Shelpai W, Qawas A. Prevalence and risk factors of cardiovascular disease in the United Arab Emirates. Hamdan Med J. 2018;11(3):105. https://doi.org/10.4103/HMJ.HMJ_37_18

7. Sasser S, Gibbs M, Blackwell T. Prehospital emergency care in Abu Dhabi, United Arab Emirates. Prehospital Emerg Care. 2004;8(1):51-7. https://doi.org/10.1080/312703002818

8. Arksey H, O’Malley L. Scoping studies: towards a methodological framework. Int J Soc Res Methodol. 2005;8(1):19-32. https://doi. org/10.1080/1364557032000119616

9. Munn Z, Peters MDJ, Stern C, Tufanaru C, Mcarthur A, Aromataris E. Systematic review or scoping review ? Guidance for authors when choosing between a systematic or scoping review approach. BMC Med Res Methodol. 2018;18(1):143. https://doi. org/10.1186/s12874-018-0611-X

10. Tricco AC, Lillie E, Zarin W, O'Brien KK, Colquhoun H, Levac D, et al. PRISMA Extension for Scoping Reviews (PRISMA-ScR): Checklist and Explanation. Ann Intern Med. 2018;169(7):467-73. https://doi.org/10.7326/M18-0850

11. Grey matters: a practical tool for searching health-related grey literature. Ottawa; Canadian Agency for Drugs and Technologies in Health; 2019 (https://www.cadth.ca/resources/finding-evidence/grey-matters, accessed 16 March 2021).

12. Ritchie J, Spencer L. Qualitative data analysis for applied policy research. In: Huberman A, Miles M, editors. The qualitative researcher's companion. Thousand Oaks, CA: SAGE Publications Inc.; 2002:305-29. 
13. Conroy KM, Jolin SW. Cardiac arrest in Saudi Arabia: a 7-year experience in Riyadh. J Emerg Med. 1999;17(4):617-23. https://doi. org/10.1016/s0736-4679(99)00049-9

14. Al Hasan D, Brightwell R. General practitioner pre-hospital resuscitation contribution to out of hospital cardiac arrest survival : a retrospective study Emerg Med Open Access. 2019;9(3):397.

15. Al Hasan D, Drennan J, Monger E, Mahmid S Al, Ahmad H, Ameen M, et al. Dispatcher assisted cardiopulmonary resuscitation implementation in Kuwait. Medicine (Baltimore). 2019;98(44):e17752. https://doi.org/10.1097/MD.0000000000017752

16. Alqahtani S, Alhajeri A, Ahmed A, Mashal S. Characteristics of out of hospital cardiac arrest in the United Arab Emirates. Hear Views. 2019;20(4):146.

17. Arabi A, Patel A, Alsuwaidi J, Singh R, Albinali H. Ethnic differences in patients with out-of-hospital cardiac arrest: insight from a 20-year registry in the State of Qatar. J Am Coll Cardiol. 2013;61(10):E15. http://dx.doi.org/10.1016/So735-1097(13)60016-9

18. Batt AM, Al-Hajeri AS, Cummins FH. A profile of out-of-hospital cardiac arrests in northern Emirates, United Arab Emirates. Saudi Med J. 2016;37(11). https://doi.org/10.15537/smj.2016.11.16126

19. Batt AM, Al-Hajeri AS, Cummins FH. Urgent need to strengthen the chain of survival in the United Arab Emirates: a letter to the editor. Emergency. 2017;5(1):5968600.

20. Bin Salleeh HM, Gabralla KA, Leggio WJ, Al Aseri ZA. Out-of-hospital adult cardiac arrests in a university hospital in central Saudi Arabia. Saudi Med J. 2015;36(9):1071-5. https://doi.org/10.15537/smj.2015.9.12081

21. Irfan FB, Bhutta ZA, Castren M, Straney L, Djarv T, Tariq T, et al. Epidemiology and outcomes of out-of-hospital cardiac arrest in Qatar: A nationwide observational study. Int J Cardiol. 2016;223:1007-13. http://dx.doi.org/10.1016/j.ijcard.2016.08.299

22. Irfan FB, Castren M, Bhutta ZA, George P, Qureshi I, Thomas SH, et al. Ethnic differences in out-of-hospital cardiac arrest among Middle Eastern Arabs and North African populations living in Qatar. Ethn Heal. 2018;1-10. https://doi.org/10.1080/13557858.2018.1 530736

23. Nadar SK, Mujtaba M, Al-Hadi H, Sadiq M, Al-Riyami A, Ali M, et al. Epidemiology, outcomes and coronary angiography findings of patients following out-of-hospital cardiac arrest: a single-centre experience from Oman. Sultan Qaboos Univ Med J. 2018;18(2):e155-60. https://doi.org/10.18295/squmj.2018.18.02.006

24. Ong MEH, Shin S Do, De Souza NNA, Tanaka H, Nishiuchi T, Song KJ, et al. Outcomes for out-of-hospital cardiac arrests across 7 countries in Asia: The Pan Asian Resuscitation Outcomes Study (PAROS). Resuscitation. 2015;96:100-8. https://doi.org/10.1016/j. resuscitation.2015.07.026

25. Patel AA, Arabi AR, Alzaeem H, Al Suwaidi J, Singh R, Al Binali HA. Clinical profile, management, and outcome in patients with out of hospital cardiac arrest: Insights from a 20-year registry. Int J Gen Med. 2014;7:373-81. https://doi.org/10.2147/IJGM.S60992

26. Salam AM, AlBinali HA, Singh R, Al Suwaidi J. Impact of the 2005 resuscitation guidelines on patient survival after out-of-hospital cardiac arrest: experience from a 20-year registry in a middle-eastern country. Resuscitation. 2013;84(8):e97-8. http://dx.doi. org/10.1016/j.resuscitation.2013.04.008

27. Salam AM, AlHabib K, Almahmeed W, Alsheikh-Ali A, Sulaiman K, Amin H, et al. Abstract 11181: Presentation with cardiac arrest in patients with acute coronary syndromes: insights from the Second Gulf Registry of Acute Coronary Events. Circulation. 2018;130(suppl 2):A11181. https://doi.org/10.1161/circ.130.suppl_2.11181

28. Batt AM, Al-Hajeri AS, Ward G, Pilapil CS, Delport S, Cummins FH. Paediatric cardiac arrests in the northern emirates, United Arab Emirates. Mediterr J Emerg Med. 2017;(25):30-4.

29. Bin Salleeh HM, Al Tom M, Ahmed Y, Leggio WJ, Abdulqader NF. Out of hospital pediatric cardiac arrest: prospective study from Riyadh, Saudi Arabia. Biosci Biotechnol Res Asia. 2016;13(1):569-72.

30. Tham LP, Wah W, Phillips R, Shahidah N, Ng YY, Shin S Do, et al. Epidemiology and outcome of paediatric out-of-hospital cardiac arrests: A paediatric sub-study of the Pan-Asian resuscitation outcomes study (PAROS). Resuscitation. 2018;125:111-7. http:// dx.doi.org/10.1016/j.resuscitation.2018.01.040

31. Gräsner JT, Lefering R, Koster RW, Masterson S, Böttiger BW, Herlitz J, et al. EuReCa ONE-27 Nations, ONE Europe, ONE Registry. A prospective one month analysis of out-of-hospital cardiac arrest outcomes in 27 countries in Europe. Resuscitation. 2016;105:188-95. https://doi.org/10.1016/j.resuscitation.2016.06.004

32. AlHabib KF, Hersi A, AlFaleh H, AlNemer K, AlSaif S, Taraben A, et al. Baseline characteristics, management practices, and in-hospital outcomes of patients with acute coronary syndromes: results of the Saudi project for assessment of coronary events (SPACE) registry. J Saudi Hear Assoc. 2011;23(4):233-9. http://dx.doi.org/10.1016/j.jsha.2011.05.004

33. Masterson S, Teljeur C, Cullinan J, Murphy AW, Deasy C, Vellinga A. Out-of-hospital cardiac arrest in the home: can area characteristics identify at-risk communities in the Republic of Ireland? Int J Health Geogr. 2018;17(1):1-11. https://doi.org/10.1186/s12942018-0126-Z

34. Glass GF, Brady WJ. Bystander intervention in out-of-hospital cardiac arrest. JAMA Netw Open. 2019;2(3):e191008. https://doi. org/10.1001/jamanetworkopen.2019.1008

35. Deakin CD. The chain of survival: Not all links are equal. Resuscitation. 2018;126:80-2. https://doi.org/10.1016/j.resuscitation.2018.02.012

36. Orla M. Abstract 229: are there any cultural barriers to automated external defibrillator use in Middle Eastern Countries? Circulation. 2011;124(suppl 21):A229. https://doi.org/10.1161/circ.124.suppl_21.A229 
37. Fares S, Zubaid M, Al-Mahmeed W, Ciottone G, Sayah A, Al Suwaidi J, et al. Utilization of emergency medical services by patients with acute coronary syndromes in the Arab Gulf States. J Emerg Med. 2011;41(3):310-6. http://dx.doi.org/10.1016/j. jemermed.2010.05.002

38. Masterson S, Teljeur C, Cullinan J, Murphy AW, Deasy C, Vellinga A. The effect of rurality on out-of-hospital cardiac arrest resuscitation incidence: an exploratory study of a national registry utilizing a categorical approach. J Rural Heal. 2019;35(1):78-86. https://doi.org/10.1111/jrh.12266

39. Masterson S, Wright P, O’Donnell C, Vellinga A, Murphy AW, Hennelly D, et al. Urban and rural differences in out-of-hospital cardiac arrest in Ireland. Resuscitation. 2015;91:42-7. http://dx.doi.org/10.1016/j.resuscitation.2015.03.012

40. OHCAR Steering Group. Out-of-hospital cardiac arrest register (OHCAR) annual report 2018. Galway, OHCAR; 2018 (http://www. xn--slnsbhilte-t4acc.ie/site/uploads/ohcar-2018-annual-report.pdf, accessed 16 March 2021).

41. OHCAR Steering Group. Out-of-hospital cardiac arrest register (OHCAR). Sixth annual report 2014. Galway, OHCAR; 2014 (https://www.phecit.ie/Images/PHECC/Publications and Media/Other Publications/5.1 OHCAR 6th Annual Report.pdf, accessed 16 March 2021).

42. Batt AM, Al-Hajeri AS, Cummins FH, Bin Salleeh H. Out-of-hospital adult cardiac arrests in a university hospital in central Saudi Arabia. Saudi Med J. 2015;37(6):714. https://doi.org/10.15537/Smj.2016.6.14852

43. Batt AM, Al-Hajeri AS, Cummins FH. Re: a profile of out-of-hospital cardiac arrests in northern emirates, United Arab Emirates. Saudi Med J. 2017;38(6):666-8. https://doi.org/10.15537/smj.2017.6.20128

44. Eisenberg M, Lippert FK, Castren M, Moore F, Ong M, Rea T. Improving survival from out-of-hospital cardiac arrest: acting on the call. Global Resuscitation Alliance; 2018. (https://www.cercp.org/images/stories/recursos/articulos_docs_interes/doc_GRA_ Acting_on_the_call_1.2018.pdf, accessed 16 March 2021).

45. Smith CM, Wilson MH, Hartley-Sharpe C, Gwinnutt C, Dicker B, Perkins GD. The use of trained volunteers in the response to out-of-hospital cardiac arrest - the GoodSAM experience. Resuscitation. 2017;121:123-6. http://dx.doi.org/10.1016/j.resuscitation.2017.10.020

46. Brooks SC, Worthington H, Gonedalles T, Bobrow B, Morrison LJ. Implementation of the PulsePoint smartphone application for crowd-sourcing bystander resuscitation. Crit Care. 2014;18(1):484. https://doi.org/10.1186/cc13674

47. Morais DA, Carvalho DV, Correa Ados R. Out-of-hospital cardiac arrest: determinant factors for immediate survival after cardiopulmonary resuscitation. Rev Lat Am Enfermagem. 2014;22(4):562-8. https://doi.org/10.1590/0104-1169.3453.2452

48. Ng YY, Leong SHB, Ong MEH. The role of dispatch in resuscitation. Singapore Med J. 2017;58(7):449-52. https://doi.org/10.11622/ smedj.2017059

49. Moran PS, Teljeur C, Masterson S, O'Neill M, Harrington P, Ryan M. Cost-effectiveness of a national public access defibrillation programme. Resuscitation. 2015;91:48-55. http://dx.doi.org/10.1016/j.resuscitation.2015.03.017

50. Lijovic M, Bernard S, Nehme Z, Walker T, Smith K. Public access defibrillation-results from the Victorian ambulance cardiac arrest registry. Resuscitation. 2014;85(12):1739-44. http://dx.doi.org/10.1016/j.resuscitation.2014.10.005

51. Cummins RO, Chamberlain DA, Abramson NS, Allen M, Baskett PJ, Becker L, et al. Recommended guidelines for uniform reporting of data from out-of-hospital cardiac arrest: the Utstein style. A statement for health professionals from a task force of the American Heart Association, the European Resuscitation Council, and Heart and Stroke. Circulation. 1991;84(2):960-75. https:// doi.org/10.1161/01.cir.84.2.960

52. Morrison A, Polisena J, Husereau D, Moulton K, Clark M, Fiander M, et al. The effect of English-language restriction on systematic review-based meta-analyses: a systematic review of empirical studies. Int J Technol Assess Health Care. 2012;28(2):138-44. https://doi.org/10.1017/S0266462312000086

53. Haddaway NR, Collins AM, Coughlin D, Kirk S. The role of Google scholar in evidence reviews and its applicability to grey literature searching. PLoS One. 2015;10(9):e0138237. https://doi.org/10.1371/journal.pone.0138237 